\title{
Resuscitation and senility: a study of patients' opinions
}

\author{
George S Robertson Aberdeen Royal Infirmary, Scotland
}

\section{Author's abstract}

In the context of 'Do-not-resuscitate' (DNR) decisions, there is a lack of information in the UK on the opinions of patients and prospective patients.

Written anonymous responses to questionnaires issued to 322 out-patient subjects showed that 97 per cent would opt for cardiopulmonary resuscitation (CPR) in their current state of health. In the hypothetical circumstance of having advanced senile dementia only 10 per cent would definitely want CPR, with 75 per cent preferring not to have CPR. There were no significant correlations between the responses and sex or age. Of 270 patients asked verbally if they found the questions disturbing, none said they did.

These findings show that the great majority of patients would not wish CPR if severely senile, and that patients are not disturbed by questions relating to their choice for or against CPR. This should encourage further investigations of patients' opinions on CPR in a broader range of conditions, and greater use of DNR orders.

\section{Introduction}

The medical profession has had experience of cardiopulmonary resuscitation (CPR) for some 30 years and of 'Do-not-resuscitate' (DNR) orders for 15 years. It might be expected that the choice of when and when not to resuscitate would now have been reasonably well clarified in respect of individual patients with particular sets of clinical conditions. There is much evidence of continuing confusion and uncertainty.

A British editorial commentary in 1983 cautioned against '... the persistent diagnostic and therapeutic endeavour associated with high-technology medicine' in dying patients (1), and another in 1985 stated that: 'On the present evidence ... there are certain groups of patients who should not be resuscitated' (2). In the intervening years, progress towards agreement on DNR policy in Britain has been

\section{Key words}

Cardiopulmonary resuscitation; DNR orders; senility. sporadic, and decisions have remained essentially the concern of doctors alone. A more recent editorial analyses the ethical principles governing DNR orders, and urges their wider use (3).

In determining the appropriateness of CPR, American doctors have shown greater willingness than their British counterparts to permit patients' opinions to influence DNR decisions, and since 1988 all hospitals in the USA seeking accreditation from the Joint Commission on Accreditation of Healthcare Organisations have been required to introduce DNR policies, and patient participation in decisions is recommended whenever possible (4). In Britain, hospitals with DNR policies are probably in a small minority, despite suggestions that most British doctors would support such policies (5).

Several studies of patients' attitudes to CPR have been conducted in the USA, and there is evidence that senile dementia more than any other condition has an association with patients' wishes for future DNR status $(6,7)$.

No British studies have tried specifically to determine the attitudes of prospective patients to resuscitation in the particular context of hypothetical senile brain disease, although it has been proposed that prior knowledge of patients' wishes would be helpful in decisions on life-sustaining treatments (8).

\section{Patients and methods}

The study was conducted in 333 unselected patients, with no evidence of cognitive impairment, attending for out-patient urological examination and/or surgery. No premedication was given and all patients received a propofol-based general anaesthetic. Patients were asked to read a simple explanation of CPR and answer anonymously three questions on a separate sheet. The questionnaires were issued at least two hours after the patients had returned from the recovery room to the ward area, at which time they were deemed to be fully recovered and 'ready for discharge' (9).

Statistical analyses for an association between responses and the sex of respondents, and between responses and age categories were carried out using Chi-square testing. Differences between the propor- 
tions of male and female patients responding 'No' to question 3 (see results) were analysed using Z-test for proportions. Within the separate groups of male and female respondents, differences in mean age related to response were analysed using one-way analysis of variance.

After completing the questionnaire 270 patients were asked verbally: 'Did you find it disturbing to be asked these questions?'

\section{Results}

Questionnaires were issued to 333 patients. Eleven patients were excluded from the study: two did not wish to complete the questionnaire; four answered 'No' and five answered 'Uncertain' to question 1: 'After reading the introduction, do you understand the meaning of "resuscitation"?

The results of the remaining 322 questionnaires are shown in Tables I and II. In response to question 2: 'In your current state of health, if you had a sudden heart attack and your heart and breathing stopped, do you think you would want to be resuscitated?', 96.58 per cent responded 'Yes', $2 \cdot 17$ per cent said 'No', and 1.24 per cent were 'Uncertain'.

In response to question 3: 'Imagine yourself to be senile and no longer able to recognise your family and friends. If you had a sudden heart attack and your heart and breathing stopped, do you think you would want to be resuscitated?', only 9.94 per cent responded 'Yes', 15.22 per cent were 'Uncertain', and 74.84 per cent would not wish to be resuscitated.

There was no significant association between the responses to question 3 and the sex of the respondents. Analysis of the mean ages of the groups of respondents showed no significant differences. Within the separate mean ages of male and female patients there were also no significant differences related to responses to question 3. Analysis of responses in those above and below age 60 showed no significant differences (Table III).

In response to the verbal question: 'Did you find it disturbing to be asked these questions?', no one responded in the affirmative.

\section{Discussion}

This study of hospital out-patients shows that threequarters would favour not being resuscitated after a cardiac arrest if they had become severely senile, and only 10 per cent would definitely opt for resuscitation. In their current state of health about 2 per cent of patients would not wish CPR, and over 96 per cent would opt for it. There is thus a marked difference in responses when the condition of advanced senile disease is introduced into the prospective clinical picture.

An early American study (10) found that only 6.6 per cent of elderly residents in an institution would

\section{Table I}

\section{Table II}

Numbers (percentages) of responses to the question: 'In your current state of health, if you had a sudden heart attack and your heart and breathing stopped, do you think you would want to be resuscitated?'

$\begin{array}{lc}\text { Response } & \text { Number of patients } \\ \text { Yes } & 311(96 \cdot 58) \\ \text { No } & 7(2 \cdot 17) \\ \text { Uncertain } & 4(1 \cdot 24)\end{array}$

Numbers (percentages) of responses to the question: 'Imagine yourself to be senile and no longer able to recognise your family and friends. If you had a sudden heart attack and your heart and breathing stopped, do you think you would want to be resuscitated?'

$\begin{array}{lr}\text { Response } & \text { Number of patier } \\ \text { Yes } & 32(9 \cdot 94) \\ \text { No } & 241(74 \cdot 84) \\ \text { Uncertain } & 49(15 \cdot 22)\end{array}$

\section{Table III}

Numbers of responses (percentages) related to age group to the question: 'Imagine yourself to be senile and no longer able to recognise your family and friends. If you had a sudden heart attack and your heart and breathing stopped, do you think you would want to be resuscitated?'

$\begin{array}{lllll}\text { Age group } & \text { Yes } & \text { No } & \text { Uncertain } & \text { Totals } \\ \text { Under } 60 & 18(9 \cdot 18) & 143(72 \cdot 96) & 35(17 \cdot 86) & 196 \\ 60 \text { and over } & 14(11 \cdot 11) & 98(77 \cdot 78) & 14(11 \cdot 11) & 126 \\ \text { Totals } & 32 & 241 & 49 & 322\end{array}$


want CPR, and a more recent investigation of opinions among competent nursing home residents (mean age 84) showed that preferences for CPR decreased significantly with envisaged increasing cognitive impairment (6). The results of the present study are broadly consistent with those previous investigations in providing evidence that increasing age is not associated with a decline in resolve to forego CPR or aggressive treatment in the presence of senile brain disease.

To the non-medical person, the word senile probably means rather more than the dictionary definition, 'showing evidence of mental and physical deterioration in old age', with concern about serious loss of mental function being particularly dominant (7). This interpretation was presumed in the deliberate use of the phrase, 'no longer able to recognise your family and friends' (Table III), which was used in a recent New York study of geriatric out-patients (11).

This represents a clinically advanced stage of senile dementia, corresponding to stage 6 of the Functional Assessment Staging of Alzheimer's Disease (FAST) described by Reisberg (12).

Alzheimer's disease, more than any other condition, appears to be associated with negative feelings towards life-sustaining treatments. In an examination of the opinions of doctors and patients relating to a range of clinical scenarios it was found that both groups ranked the hypothetical presence of Alzheimer's disease highest for not wishing resuscitation after a cardiac arrest (7). More recently, a study of DNR orders written for patients in an emergency department over a 10-month period showed that, apart from the various acute illnesses which prompted the emergency admissions, the most common underlying problem associated with DNR status was senile dementia (13). A recent American editorial states that: '. . . DNR orders often should be considered for patients with senile dementia' (14).

The ethical basis for DNR decisions and those who should make such decisions have been the subjects of several recent commentaries. Increasingly, DNR decisions are perceived as being less a purely medical judgement and more an expression of at least some degree of patient autonomy. The underlying ethical principles for decisions to forego lifesustaining treatment (which would include CPR) have recently been summarised by the Appleton International Conference under the headings of autonomy, beneficence (do good), non-maleficence (avoid harm), and justice (15), and similar ethical guidelines have been proposed by the Council on Ethical and Judicial Affairs of the American Medical Association (16).

Several commentators have argued the supremacy of the patient's self-determining right to decline CPR. Since this can be achieved only in a proleptic manner, American groups in particular have strongly advocated early discussion of CPR and DNR. A recurring argument against such a policy is the potential for causing psychological upset, but there is little evidence to support this fear (17). In a recent study of patients aged 65 to 90 , Stelter et al found that no fewer than 95 per cent wanted the ability to make or influence decisions at the end of life (18). In the present study, of the 270 patients asked if the questions had been disturbing, none expressed any upset, and individual comments were volunteered, such as: 'This should have been asked years ago!', 'Not at all - it's a fact of life,' and 'We need to know we won't be kept alive indefinitely'. The total absence of avowed disturbance to patients was of particular interest and surprise to the nursing staff of the out-patient unit who initially expressed grave reservations about the wisdom of asking such seemingly sensitive questions. The lack of upset is taken to indicate that patients in general have a realistic attitude to the aims and limitations of CPR, and it provides supporting evidence for the findings of American studies suggesting that patients feel more comfortable with discussions of these matters than do their doctors $(19,20)$.

The American Medical Association guidelines (16) state that 68 per cent of patients want to discuss CPR, and note that although only 11 per cent of patients are mentally impaired at the time of admission to hospital, 76 per cent are impaired at the time when a DNR order becomes an obvious medical option. Thus, even within the more enlightened status of DNR policies in the United States, decisions are often taken too late to allow the patient any expression of opinion.

Despite pleas for the supremacy of patient autonomy, others have argued that clinical judgement may be more relevant for making DNR decisions, suggesting that considerations of futility, prognosis, and expected quality of life may be better determinants of whether or not to resuscitate. Tomlinson and Brody (21), in discussing the rationale for DNR decisions state that in a situation where no medical benefit is likely, there is no obligation to treat. They suggest that this is purely a medical decision: 'The right to self-determination ... is irrelevant to the determination that resuscitation would be of no medical benefit.' Murphy (22) also takes the view that not resuscitating severely demented patients has more to do with judgements of futility, or balancing benefits and burdens - supposedly an essentially medical judgement. Youngner (23) takes issue with this assessment and states: 'Murphy's proposal is a regressive step. Under the guise of medical expertise and concern for proper resource allocation it encourages physicians to substitute their own value judgements for those of their patients.'

It is evident that medical judgements in favour of some DNR decisions can rightly be informed by clinical experience, unbiased research, and the results of outcome determinations which would not 
normally be within the ken of patients or their relatives. Such knowledge relates to the ethical principles of beneficence and non-maleficence, and possibly to the principle of justice in the use of expensive medical facilities. Thus it may appear that medical judgements of futility have little to do with patient autonomy, but central to the doctor-patient relationship are informed consent, truth-telling, and a sharing of values. At the very least, patients or their relatives should be informed of the reasons behind a 'medical' DNR decision.

The respective roles of the ethical principles involved in DNR decisions will be determined by individual case circumstances. However, a unifying influence upon the final decision-making process ought to be improved systems of communication. There is evidence of widespread failures in, for example, the documentation of DNR decisions, even within systems designed to improve communication in some UK hospitals $(5,24)$.

This study leads to the conclusion that the great majority of people would not want CPR if severely affected by senile dementia, and that patients are not disturbed by discussing resuscitation and DNR in the out-patient setting. This ought to encourage the more widespread introduction of DNR policies, and these should usually include competent evidence of patients' wishes.

George $S$ Robertson, MD, FFARCS is a Consultant Anaesthetist at Aberdeen Royal Infirmary and an Honorary Clinical Senior Lecturer in Anaesthetics in the University of Aberdeen. Dr Robertson is in receipt of a medical ethics research grant from Grampian Health Board Endowment Funds. Correspondence address: Department of Anaesthetics, Aberdeen Royal Infirmary, Foresterhill, Aberdeen AB9 2ZB.

\section{References}

(1) Anonymous. Should dying be a diagnosis? [editorial]. Lancet 1983; ii: 261.

(2) Searle J F. Not to be resuscitated [editorial]. Anaesthesia 1985; 40: 617-618.

(3) Gillon R. Resuscitation policies - action required [editorial]. Fournal of medical ethics 1992; 18: 115-116.

(4) Cohen C B, Cohen P J. Do-not-resuscitate orders in the operating room. New England journal of medicine 1991; 325: 1879-1882.

(5) Aarons E J, Beeching N J. Survey of 'Do not resuscitate' orders in a district general hospital. British medical journal 1991; 303: 1504-1506.

(6) Cohen-Mansfield J, Rabinovich B A, Lipson S et al. The decision to execute a durable power of attorney for healthcare and preferences regarding the utilization of life-saving treatments in nursing home residents. Archives of internal medicine 1991; 151: 289-294.
(7) Ebell M H, Doukas D J, Smith M A. The do-notresuscitate order: a comparison of physician and patient preferences and decision-making. American journal of medicine 1991; 91: 255-260.

(8) Robertson G S. Dealing with the brain-damaged old dignity before sanctity. Fournal of medical ethics 1982; 8: 173-179.

(9) Millar J M, Jewkes C F. Recovery and morbidity after daycase anaesthesia. Anaesthesia 1988; 43: 738-743.

(10) Wagner A. Cardiopulmonary resuscitation in the aged. A prospective survey. New England journal of medicine 1984; 310: 1129-1130.

(11) Seckler A B, Meier D E, Mulvihill M, Paris B E C. Substituted judgement: how accurate are proxy predictions? Annals of internal medicine 1991; 115: 92-98.

(12) Reisberg B. Dementia: a systematic approach to identifying reversible causes. Geriatrics 1986; 41: 30-46.

(13) Wrenn K, Brody S L. Do-not-resuscitate orders in the emergency department. American journal of medicine 1992; 92: 129-133.

(14) Fox E, Siegler M. Redefining the emergency physician's role in do-not-resuscitate decision-making [editorial]. American journal of medicine 1992; 92: 125-128.

(15) The Appleton International Conference: Developing guidelines for decisions to forgo life-prolonging medical treatment. Fournal of medical ethics 1992; 18 (suppl): 3-5.

(16) Council on Ethical and Judicial Affairs, American Medical Association. Guidelines for the appropriate use of do-not-resuscitate orders. Fournal of the American Medical Association 1991; 265: 18681871.

(17) Emergency Cardiac Care Committee and Subcommittees, American Heart Association. Guidelines for cardiopulmonary resuscitation and emergency cardiac care, VIII: ethical considerations in resuscitation. Fournal of the American Medical Association 1992; 268: 2282-2288.

(18) Stelter K L, Elliott B A, Bruno C A. Living will completion in older adults. Archives of internal medicine 1992; 152: 954-959.

(19) American Medical Association white paper on elderly health. Report of the Council on Scientific Affairs. Archives of internal medicine 1990; 150: 24592472.

(20) Gleeson K, Wise S. The do-not-resuscitate order. Still too little too late. Archives of internal medicine 1990; 150: 1057-1060.

(21) Tomlinson T, Brody H. Ethics and communication in do-not-resuscitate orders. New England journal of medicine 1988; 318: 43-46.

(22) Murphy D J. Do-not-resuscitate orders. Time for reappraisal in long-term care institutions. Fournal of the American Medical Association 1988; 260: 2098-2101.

(23) Youngner S J. Who defines futility? fournal of the American Medical Association 1988; 260: 2094-2095.

(24) Stewart K, Abel K, Rai G S. Resuscitation decisions in a general hospital. British medical journal 1990; 300 785 . 